Review

\title{
Etiology of myasthenia gravis: Innate immunity signature in pathological thymus
}

\author{
Paola Cavalcante ${ }^{\mathrm{a}}$, Perrine Cufi ${ }^{\mathrm{b}}$, Renato Mantegazza ${ }^{\mathrm{a}}$, Sonia Berrih-Aknin ${ }^{\mathrm{b}}$, \\ Pia Bernasconi ${ }^{\mathrm{a}, *, 1}$, Rozen Le Panse ${ }^{\mathrm{b}, 1}$ \\ a Department of Neurology IV, Neuromuscular Diseases and Neuroimmunology, Fondazione Istituto Neurologico 'Carlo Besta', Milan, Italy \\ b Unité mixte de recherche - CNRS UMR7215/INSERM U974/UPMC UM76/AIM - Thérapie des maladies du muscle strié, Groupe hospitalier Pitié-Salpêtrière, 105 Boulevard de l'Hôpital, Paris \\ 75651 Cedex 13 - France
}

\section{A R T I C L E I N F O}

\section{Article history:}

Accepted 12 March 2013

Available online 25 March 2013

\section{Keywords:}

Myasthenia gravis

Etiology

Thymus

Inflammation

Toll-like receptors

Viral infection

\begin{abstract}
A B S T R A C T
Myasthenia gravis (MG) is an autoimmune disease affecting the neuromuscular junction (NMJ), whose clinical hallmark is muscle weakness and early fatigability. The main target of autoimmunity in MG is the acetylcholine receptor (AChR) located in the NMJ. It is now widely accepted that the thymus is probably the prime site of autoimmunity development and maintenance in AChR-positive MG patients; however, the exact mechanisms triggering and perpetuating the intra-thymic autoimmune response to AChR are still unknown. As with many autoimmune diseases, MG has a multifactorial etiology, resulting from complex interactions between genetic and environmental factors, as fully described in this review. Among environmental factors, viral infections could play a central role in autoimmunity, mainly through the induction of dysregulated Toll-like receptor (TLR)-mediated innate immune responses, which can lead to inflammation and adaptive autoimmune response. Growing evidence of chronic inflammation, TLR activation, and persistent viral infections in the thymus of MG patients, strongly supports the hypothesis that, in the context of a genetic susceptible background, the intrathymic innate immune responses to pathogen infections might contribute to MG etiology.
\end{abstract}

(C) 2013 Elsevier B.V. All rights reserved.

\section{Contents}

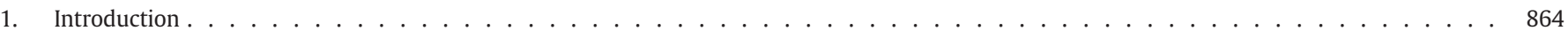

2. Genetic and environmental factors related to MG etiology . . . . . . . . . . . . . . . . . . . . . . . . . . 864

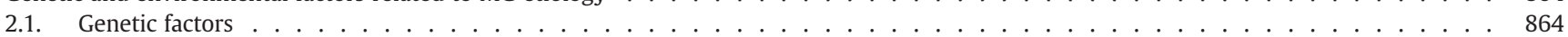

2.1.1. The HLA genomic region . . . . . . . . . . . . . . . . . . . . . . . . . . 864

2.1.2. Non HLA-related genes associated with MG . . . . . . . . . . . . . . . . . . . . . . . . . 865

2.1.3. Genome-wide association studies on MG patients . . . . . . . . . . . . . . . . . . . . . . . . . . . 865

2.2. Gender influence . . . . . . . . . . . . . . . . . . . . . . . . . . . . . . . . . . . . . . . . . . . . . . . . . . . .

2.3. Drug-induced $\mathrm{MG} \ldots \ldots \ldots \ldots \ldots$

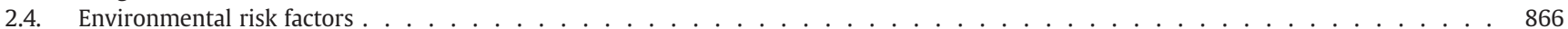

3. Thymus pathology: a dominant feature of AChR-MG . . . . . . . . . . . . . . . . . . . . . . . . 866

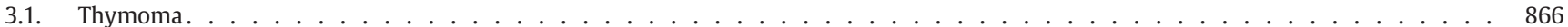

3.2. Thymic hyperplasia . . . . . . . . . . . . . . . . . . . . . . . . . . . . . . . . . . . . . . . . . . . . .

3.3. The inflammatory status of MG thymus: the IFN imprinting . . . . . . . . . . . . . . . . . . . . . . . 867

4. Link between innate immunity and autoimmunity in $\mathrm{MG} \ldots \ldots \ldots$

4.1. Overview of the role of innate immunity in autoimmunity . . . . . . . . . . . . . . . . . . 868

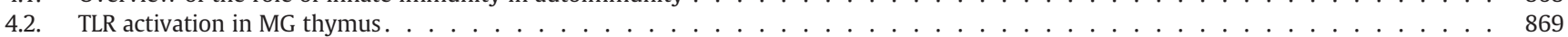

4.3. Role of viral infections in thymic MG pathogenesis. . . . . . . . . . . . . . . . . . . . . . . 869

Abbreviations: AChR, acetylcholine receptor; EAMG, experimental autoimmune MG; EBV, Epstein-Barr virus; ENOX1, ecto-NADH oxidase 1 gene; EOMG, early-onset MG; GC, germinal center; GWAS, genome-wide association studies; HLA, human leukocyte antigen; IFN, interferon; IL, interleukin; IRF, interferon regulatory factor; LRP4, lipoprotein receptor-related protein 4; LOMG, late-onset MG; MG, myasthenia gravis; MuSK, muscle specific kinase; NMJ, neuromuscular junction; PTPN22, protein tyrosine phosphatase nonreceptor-22; PV, poliovirus; TLR, Toll-like receptor; TNF- $\alpha$, tumor necrosis factor- $\alpha$; TNIP1, TNF- $\alpha$-induced protein 3 (TNFAIP3)-interacting protein 1.

* Corresponding author. Tel.: + 3902 23942255; fax: + 390270633874

E-mail address: pbernasconi@istituto-besta.it (P. Bernasconi).

1 Equal contribution. 


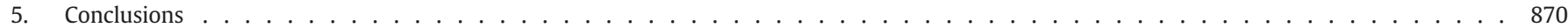

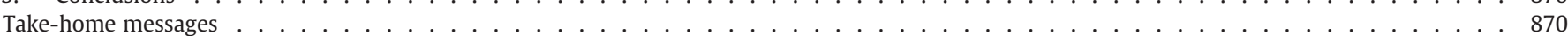

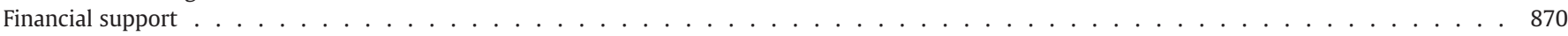

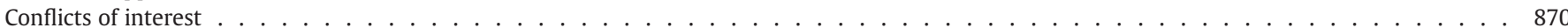

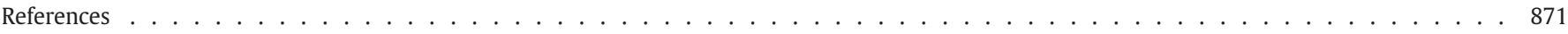

\section{Introduction}

Myasthenia gravis (MG) is an autoimmune disease of the neuromuscular junction (NMJ) in which muscle weakness and abnormal fatigability on exertion are the prominent clinical features; symptoms are due to neuromuscular transmission impairment caused by autoantibodies targeting postsynaptic membrane proteins of the striated skeletal muscles. Over $80 \%$ of patients have antibodies against acetylcholine receptor (AChR) [1] or clustered AChRs [2,3] and variable proportions (37.5-70.0\%) of AChR-negative patients have antibodies to the muscle kinase receptor (MuSK) [4-10]. Recently, autoantibodies to the lipoprotein receptor-related protein 4 (LRP4) have been detected in variable proportions of AChR- and MuSK-negative (seronegative) MG patients [11-13] (Table 1).

MG patients can be distinguished in purely ocular and generalized forms and in early-onset (EOMG; under 40 years old) or late-onset (LOMG; over 40 years old) forms. At onset, extraocular muscles are often the first ones to be affected and may remain the only muscles involved (pure ocular MG); however, in many cases ocular disease progresses and involves skeletal or bulbar muscles, giving rise to the generalized form of MG [1]. Distribution of age at MG onset shows a female-dominant peak in EOMG and a male-dominant peak in LOMG [14]. In the recent years, the incidence of MG in the elderly (over 50 years old) population is increasing, likely due to aging, improved recognition and diagnosis of the disease or to unknown environmental factors [15-17].

In AChR-MG, correlation between disease severity and anti-AChR antibody titers is poor, hence the antibody prognostic value is poor [18]. MuSK-MG patients present often with more severe symptoms than AChR-MG patients. They have prominent bulbar and facial weakness associated with marked muscle atrophy and are less responsive to treatments [6]. Seronegative MG patients are instead clinically indistinguishable from AChR-MG patients [19].

Growing evidence supports the involvement of the thymus in the pathogenesis of MG. The role of this organ as a prime site of autosensitization and autoimmunity is widely accepted in AChR-MG patients. In these patients, the thymus exhibits morphological and functional abnormalities, usually characterized by a thymoma or by hyperplasia [20,21]. In MuSK-MG patients, the thymic contribution to the disease remains unclear (see Section 3 for an extensive review of the thymic MG pathogenesis).

Like other autoimmune diseases, MG is multifactorial and its manifestation results from the combination and interaction of multiple genetic and environmental risk factors. AChR-MG occurring in EOMG patients and presenting with thymic hyperplasia is the most common, and also the best characterized, subtype of MG. Although anti-AChR autoantibodies have been identified almost forty years ago [22], the exact immunological mechanisms underlying the autoimmune response are still unknown. Current treatments are quite effective but complete stable remission is observed only in a proportion of patients; these observations highlight the need of better understanding the specific factors and events initiating or perpetuating the disease [23]. A more comprehensive understanding of the genetic and environmental factors associated with MG and demonstration of the pathologically relevant gene-environment interactions are crucial for improving our knowledge in MG pathogenesis.

In this manuscript, we review early and more recent data on genetic and environmental risk factors associated with MG, giving particular emphasis on the emerging role of viral infections and innate immunity in the intrathymic pathogenesis of the disease.

\section{Genetic and environmental factors related to MG etiology}

MG is a multifactorial disease and appears likely to be linked to a combination of predisposing factors and triggering event(s). In thymomaassociated MG, the development of thymic epithelial tumors is a clear pathogenetic event, even if thymoma is not always associated with MG. In the other forms of autoimmune MG, the event leading to the disease is not clearly defined.

\subsection{Genetic factors}

Autoimmune MG does not show any Mendelian hereditary. However, as for many autoimmune diseases, a genetic risk accounts for some responsibility in the disease development, as attested by the $40 \%$ concordance rate in monozygotic twins [24].

\subsubsection{The HLA genomic region}

The association of human leukocyte antigen (HLA) class I and class II genes with MG is clearly established [25]. These genes comprise several hundreds of alleles on the chromosome 6 p21 region, encoding membrane-bound molecules of the immunoglobulin superfamily that present antigenic epitopes to lymphoid cells. In Caucasian MG patients, a strong genetic association is observed between the HLA A1-B8-DR3 haplotype and EOMG patients [26]. The HLA-DR3 and B8 alleles are part of the most conserved HLA haplotype in European populations, the "so-called" 8.1 haplotype that associates the HLA-B8 allele with DR3, along with alleles of many other HLA loci, such as HLA-A1. This haplotype has been associated with several autoimmune conditions, including rheumatoid arthritis [27] and systemic lupus erythematosus [28], which often co-occur in MG patients [29]. The 8.1 haplotype was found to have a strong and complex genetic effect on phenotype in EOMG associated with thymic hyperplasia, including high serum titers of AChR autoantibodies [25]. However, because of strong linkage disequilibrium extending across this haplotype, the causative alleles are not known yet. Some studies pointed to a major contribution of HLA-DQ alleles to MG, as DQB1*0502 which has been associated with MG Italian population [30]. A recent study demonstrated novel associations between HLA-DQ loci and EOMG in southeast Texas patients, not previously reported in European MG patients, suggesting that region-specific environmental factors may interact with HLA genes to predispose toward MG [31]. The role of this specific HLA haplotype in MG is not clear. Nevertheless, peripheral blood mononuclear cells from HLA-B8, DR3-positive and DR3-negative individuals differ in their ability to produce interleukin (IL)-2, IL-5, IL-12 and interferon type II (IFN-II) upon stimulation [32].

Other genetic associations have been recently pointed out for different MG forms. A study has demonstrated a genetic association between the HLA DRB1*15:01 haplotype and LOMG patients [33]. In MuSK-MG, the disease has been associated with the HLA-DR14-DQ5 haplotype in a Dutch cohort [34] and with the HLA-DR14-DQ5 and HLA-DR16-DQ5 haplotypes in an Italian population [35], suggesting a major role for the DQ5 allele in this MG subtype.

In MG patients with thymoma, studies associating MG with HLA I and II alleles did not give reproducible results [36,37]. A recent 
Table 1

Autoantibody profile in MG patients: summary of the key features.

\begin{tabular}{|c|c|c|c|c|}
\hline MG form & AChR & MuSK & LRP4 & Clustered AChR \\
\hline $\begin{array}{l}\% \text { of antibody positive } \\
\text { patients }\end{array}$ & $80-85 \%$ & $5-8 \%$ & $\sim 2-3 \%$ & $\sim 5 \%$ \\
\hline Antibody pathogenicity & $\begin{array}{l}\text { Tested in animal model } \\
\text { and in vitro }\end{array}$ & $\begin{array}{l}\text { Tested in animal model } \\
\text { and in vitro }\end{array}$ & Tested in vitro & Tested in vitro \\
\hline Isotypes & $\operatorname{IgG} 1, \operatorname{IgG} 3$ & $\operatorname{IgG} 4$ & IgG1 & - \\
\hline Role of complement & Yes & No & Yes & Likely \\
\hline $\begin{array}{l}\text { Correlation with disease } \\
\text { severity }\end{array}$ & No & Yes & Unknown & Unknown \\
\hline Thymic pathology & $\begin{array}{l}\text { Hyperplasia in most EOMG; } \\
\text { Thymoma or thymic atrophy } \\
\text { in most LOMG }\end{array}$ & $\begin{array}{l}\text { Involuted thymus resembling } \\
\text { those of age-matched controls }\end{array}$ & Unknown & Likely similar to AChR-MG \\
\hline
\end{tabular}

investigation of the association of the HLA-A locus in French Caucasian patients with thymoma revealed a protective effect of HLA-A02 in patients with a $\mathrm{B} 2$ type thymoma (World Health Organization classification) and the increased frequency of HLA-A25 in all the MG patients with thymoma analyzed [37]. In northern Chinese population, HLA-DQA $1 * 0401$ and HLA-DQB $1 * 0604$ were recently associated with thymoma-associated MG and it was suggested that different genetic mechanisms may characterize MG patients with and without thymoma [38].

Interestingly, polymorphisms on genes, different from HLA class I and II, located in the $6 \mathrm{p} 21$ chromosomal region, are also associated with MG susceptibility. This is the case for the tumor necrosis factor (TNF- $\alpha$ ) locus: peripheral blood mononuclear cells (PBMC) from patients with specific TNF- $\alpha$ polymorphisms showed higher secretion of TNF- $\alpha$ when activated in vitro $[39,40]$. Interestingly, TNF- $\alpha$ was shown to be also implicated in the development of EAMG [41].

\subsubsection{Non HLA-related genes associated with $M G$}

Polymorphisms on genes in chromosomal regions different from 6 p21 have been associated with MG, although they are also often associated with other autoimmune diseases: these are cytotoxic lymphocyte-associated protein-4 (CTLA4) [42], IFN-II, IL-10, IL-12 [43] and protein tyrosine phosphatase nonreceptor-22 (PTPN22) $[44,45]$. The rs2476601 (R620W) functional variant in the PTPN22 gene, which encodes a tyrosine phosphatase primarily expressed in lymphoid tissues, was associated with several autoimmune conditions $[46,47]$ and showed ability to interfere with autoreactive B-cell removal and increase $\mathrm{T}$ - and dendritic-cell responsiveness [47-49]. In MG, no reproducible associations were obtained in French and Italian patients: the PTPN22 rs2476601 variant was associated with MG in French population [50] but not in Italian population, in which the variant was not associated with either MG itself or any MG characteristic [51]. However, another PTPN22 polymorphism, the rs2488457 variant of the promoter region, was associated with low autoantibody titers and mild MG in the Italian cohort, suggesting a role of this variant in MG [51]. Recently, the PTPN22 gene was also reported as a risk factor for MG associated with thymoma: the PTPN22 gain-of-function 1858 T variant correlated with low IL-2 expression in thymomas, thus implying weaker T-cell receptor signaling. This result suggested that the $1858 \mathrm{~T}$ variant may predispose to MG in a subgroup of thymoma patients possibly by impeding central tolerance induction [52].

Among non-HLA loci, of particular interest is the locus coding for $\alpha-A C h R$ that is the main target of autoantibodies in MG patients. Giraud et al. identified a functional bi-allelic variant in the promoter of the $\alpha$-AChR which is associated with EOMG patients. This variant prevents binding of interferon regulatory factor 8 (IRF8) and decreases $\alpha$-AChR promoter activity in thymic epithelial cells in vitro. In a French cohort of MG patients, this variant appears to be more frequent in MG patients with an odds ratio of 2.35 , but only in patients with an early onset of disease (under 21 years old) [53]. This decrease could alter central tolerance and lead to the escape of AChR-specific autoreactive $\mathrm{T}$ cells from the thymus.

\subsubsection{Genome-wide association studies on MG patients}

Genome-wide association studies (GWAS) aimed at analyzing common genetic variations across the entire human genome in an unbiased manner in order to identify genetic risk factors associated with specific diseases. In a review on GWAS carried out on autoimmune disorders, Lettre et al. underline the discovery of polymorphisms on genes related to both adaptive immunity and innate immunity, and in particular on IL and IL receptor genes [54]. A GWAS has been very recently carried out on 649 North European EOMG patients. As expected the strongest association was found within HLA loci and, in particular, in a HLA class I region (rs7750641) that encodes TCF19. TCF19 is one of the transcription factors involved in cell proliferation or differentiation being upregulated in human pro-B and pre-B cells [55]. It is also highly expressed in germinal center (GC) cells. This locus has also been associated with type I diabetes [56]. Moreover, from this GWAS two loci were also extracted: rs2476601 corresponding to PTPN22, already described above (Section 2.1.2), and rs4958881 for TNF- $\alpha$-induced protein 3 (TNFAIP3)-interacting protein 1 (TNIP1, also known as ABIN-1, Naf1 and VAN). A growing number of references has implicated TNIP1 in chronic inflammatory diseases, such as systemic lupus erythematosus and psoriatic arthritis, through GWAS and expression studies [57,58]. TNIP1 is a signaling transduction protein that inhibits both transduction by transmembrane receptors, such as TNF- $\alpha$ receptor, epidermal growth factor receptor and Toll-like receptors (TLRs), and nuclear receptors, such as peroxisome proliferator activated receptors (PPARs) and retinoic acid receptors (RARs). These receptors play key roles in regulating inflammation and inflammatory diseases [59]. Mice with a knock-in mutation disrupting the ubiquitin-binding of TNIP1 developed the hallmarks of autoimmunity, including spontaneous formation of GC, isotype switching, and production of autoreactive antibodies. Autoimmunity was suppressed by crossing to MyD88 ${ }^{-/-}$mice, demonstrating that TLR-MyD88 signaling pathways are needed for the phenotype to develop [60]. However, the polymorphism observed in the GWAS on TNIP1 in MG patients is not located in the ubiquitin-binding or protein interaction regions. In other inflammatory diseases where TNIP1 has been involved, the polymorphisms observed were spotted on different sites. The exact role of TNIP1 remains to be elucidated both in normal physiology and in diseases.

Another large genomic study of SNPs on candidate genes on about a thousand of EOMG patients is currently in progress and might also shed light on other genes associated with a higher MG susceptibly risk.

Homozygosity mapping is an efficient gene mapping method applicable to rare recessive disorders in inbred populations. A genome-wide homozygosity study has been performed in kindred with parental consanguinity (5 of 10 siblings) with LOMG [61]. A homozygous single nucleotide variant was found in the 3 '-untranslated region of the ectoNADH oxidase 1 gene (ENOX1) in 4 affected siblings and 1 unaffected 
sibling, while the ENOX1 sequence variant was not found in 764 controls. ENOX proteins are growth-related cell surface enzymes that catalyze hydroquinone oxidation and protein disulfide-thiol interchange. In principle, the ENOX1 mutation might predispose to MG by affecting the motor endplate and/or the autoimmune response. However, it is not clear how a genetically mediated reduction in the amount of ENOX1 efficiently causes LOMG development and the exact role of ENOX1 remains to be investigated in larger cohorts of MG patients [61].

Growing numbers of novel susceptibility loci have been identified in autoimmune diseases through the development of high-throughput genotyping techniques. Now the path to understand the link between changes in genome sequences and disease predisposition, progression and/or chronicity might still be long. Beyond pure genetic analyses, numerous studies are also in progress to determine the impact of epigenetic modifications on selected genes that might play a central role in autoimmune diseases.

\subsection{Gender influence}

As for many autoimmune diseases, there is a gender bias in MG patients $[62,63]$. MG is more frequently observed in women with a 2-4:1 female bias according to studies. In EOMG with thymic hyperplasia, the bias is even stronger with a 9:1 ratio [64]. What can predispose women to autoimmunity and in particular to MG? Hormonal or genetic effects have been debated. Steroid hormones, namely estrogen, progesterone and testosterone, may influence different cells of the immune system by modulating cell proliferation, cytokine production and antibody production [65]. An enhanced susceptibility to EAMG is observed in C57BL/6 mice treated with $17 \beta$-estradiol before antigen (T-AChR) priming [66]. In contrast, knock-out mice for the estrogen receptor- $\alpha$ are equally susceptible to EAMG as wild-type C57BL/6 mice suggesting that increased susceptibility to EAMG is more likely related to increased levels of estrogen than a decrease. However, EAMG model does not reflect properly the human disease as it does not resume thymic changes of MG patients. Hormones could influence thymopoïesis and affect central tolerance. Estrogen receptors are expressed on thymocytes and thymic stromal cells and estrogen decreases thymus size $[67,68]$. We found an increased expression of estrogen receptor- $\alpha$ on thymocytes from MG patients that, consequently, could be more sensitive to the effects of estrogen. This up-regulation could be due to the inflammatory environment characteristic of the thymus of MG patients [68].

A role of sex chromosomes in autoimmunity has also been proposed including several possible mechanisms such as fetal microchimerism, $\mathrm{X}$-chromosome inactivation patterns, and $\mathrm{X}$-chromosome duplication, but so far nothing has been related to MG [69].

\subsection{Drug-induced $M G$}

D-penicillamine is a metabolite of penicillin, although it has no antibiotic properties. It is used, as a chelating agent to treat Wilson's disease, but also as an immunosuppressor to treat rheumatoid arthritis. However, the use of D-penicillamine has been associated with various immune-mediated complications, including MG. MG is reported to occur in $1 \%$ to $7 \%$ of all patients on D-penicillamine and discontinuation of the treatment leads usually to complete resolution of MG [70]. The symptoms in D-penicillamine-induced MG are usually mild but clearly associated with the presence of anti-AChR antibodies. However, a recent study reports the development of an anti-AChR and anti-MuSK MG after D-penicillamine treatment in a patient with scleroderma [71]. The mechanisms involved in D-penicillamine effects are unclear. A specific genetic susceptibility in the HLA class II region (DR1 and/or DR7) has been suggested in patients with a D-penicillamine-induced MG form [26].

Numerous case reports in the medical literature illustrate the fact that IFN- $\alpha$ or IFN- $\beta$ therapies can trigger the development of certain autoimmune diseases, including MG [72]. The implication of IFN- $\alpha / \beta$ in MG has long been suggested in various ways but never clearly defined. We recently demonstrated that IFN- $\beta$ could play a central role in MG development: IFN- $\beta$, which is overexpressed in the thymus of MG patients, can mediate the effects of dsRNA activation and trigger a specific overexpression of $\alpha$-AChR subunit [73] (see detail in Section $4.2)$.

\subsection{Environmental risk factors}

Numerous factors have been put forward in the last decade to explain the higher risk of developing an autoimmune disease in industrialized countries: these include pollution, better hygienic conditions, and microbiota changes [74]. None of them has been clearly addressed in the case of MG. Nevertheless, a recent study has revealed that plasma levels of vitamin D are significantly lower in patients with MG compared with healthy controls [75] suggesting that vitamin D deficiency could affect MG risk and progression, as in multiple sclerosis [76] and other autoimmune diseases [77].

Many MG patients, when asked if they can relate the onset of disease to "something", can also quote different environmental factors, such as stress, loss of a close relative, fatigue, and infections.

Pathogens are major environmental factors for driving/perpetuating autoimmunity $[74,78]$. Viral infections have been associated with the development of several autoimmune diseases, mainly by seroepidemiologic and immunologic studies [79]. For example, type $1 \mathrm{di}-$ abetes has been associated with coxsackievirus and cytomegalovirus, multiple sclerosis with Epstein-Barr virus (EBV) and measles virus, and rheumatoid arthritis and systemic lupus erythematosus with EBV [78]. However, since the onset of an autoimmune disease can occur well after a possible triggering infection, when the pathogen might have already been cleared or the antiviral immune responses might have subsided ("hit-and-run" hypothesis) [78], the link of infections with autoimmune diseases has been elusive. Nevertheless, accumulating evidence tends to support the idea of a contribution of viruses in promoting, exacerbating or maintaining autoimmune conditions [80].

In the following sections, after a general overview on the thymic pathology in MG patients, we will discuss the role of innate immunity in autoimmunity and the emerging contribution of viral infections and innate immune system to the intra-thymic pathogenesis of AChR-MG.

\section{Thymus pathology: a dominant feature of AChR-MG}

Pathological alterations of the thymus are found in approximately $80 \%$ of AChR-MG patients with generalized disease (Table 1 ). The most frequent change is thymic hyperplasia, observed in $50-60 \%$ of these patients, thymoma represents approximately $15 \%$ of patients and $10-20 \%$ of AChR MG cases have an atrophic or involuted thymus mainly consisting of adipose tissue with residual areas of thymic parenchyma [20]. Hyperplasia is the most common alteration in EOMG, whereas thymoma and involuted thymus are predominant in LOMG. In MuSK-MG patients no thymic histological alterations are usually found; thymectomized seronegative MG patients reveal thymic hyperplastic changes very similar to those found in AChR-MG patients (Table 1) [81,82].

\subsection{Thymoma}

Thymoma in the vast majority of cases is a slow-growing, capsulated epithelial tumor of the thymic gland, commonly presenting in middle or old age; infrequently thymoma can develop at young age and behave as a locally invasive tumor. Thymoma is frequently associated with the presence of autoimmune diseases, with MG occurring in about $30 \%$ of all patients with thymomas [83]. Thymic epithelial neoplasms mostly consist of transformed epithelial cells, surrounded 
by numerous maturing polyclonal $\mathrm{T}$ cells (thymocytes). The immature $T$ cells are doubly positive for CD4 and CD8, a phenotype that characterize $\mathrm{T}$ cells in the cortex of the normal thymus. Type B2 thymoma (World Health Organization classification) [84] is most often associated with MG, followed by types $A B$ and B1 [85].

The fact that MG patients with thymoma have always anti-AChR antibodies strongly suggests that the neoplastic transformation of thymus plays an important role in the initiation of the autoimmune response to AChR. Features of thymoma that may explain T-cell selection impairment and anti-AChR autoimmunity are: a) the lack of a functional tolerogenic autoimmune regulator (AIRE)-positive thymic medulla (in types $\mathrm{A}, \mathrm{AB}$, most $\mathrm{B} 2$ and $\mathrm{B} 3$ tumors) and the occurrence of thymic cortex-like areas (in type B1 thymomas) [86]; b) the presence of a thymic epithelium defective in the expression of HLA class II molecules [87]; c) the lack or reduction of tolerogenic AChR-positive thymic myoid cells; and d) failure to generate FOXP3-positive regulatory T cells $[83,88]$.

\subsection{Thymic hyperplasia}

The hyperplastic thymus is characterized by the presence of B lymphocyte infiltrates invading the thymic medulla or present in perivascular spaces that are fused with the thymic medulla. B-cell infiltrates can be present in the form of ectopic B-cell follicles with inclusion of GCs (follicular hyperplasia) or can be distributed throughout the medullary parenchyma (diffuse hyperplasia or thymitis) $[20,89]$. An overall increased expression of immunoglobulin genes, independent of antigenic specificity has been observed in MG thymuses demonstrating the large diversity of B cells in MG thymuses [90,91]. This observation is supported by the observation that thymic GCs contain B-cells undergoing somatic hypermutation and antigen-driven selection producing a heterogeneous population of B cells [92]. The thymus of MG patients has been shown to include all the components of the antiAChR response including B cells producing anti-AChR antibodies [93]. In hyperplastic MG thymus, GCs are usually surrounded by or contain muscle-like myoid cells that express complete adult and fetal-type AChR [94] or other muscle proteins [95]. Myoid cells, along with thymic epithelial cells, that express isolated AChR subunits [96], are suspected to play a direct role in intra-thymic autosensitization to AChR, by driving abnormal antigen presentation or cross-presentation through professional antigen presenting cells. Complement activation has been demonstrated on thymic epithelium and myoid cells in close proximity to GCs in hyperplastic thymus suggesting that autoantibody attack and complement-mediated damage to myoid cells could be responsible to favor autoantigen (i.e. AChR) availability to antigen presenting cells, and predisposing to GC formation and antibody diversification; all these events could promote the generation of self-sustained AChRspecific autoimmune response [97]. Autoreactive T-cells [98] and plasma cells producing anti-AChR antibodies [99] have been isolated from hyperplastic MG thymuses, suggesting that in AChR-MG patients the autoimmune effector arms are actively operating in the thymic gland. The role of thymus in the generation of an autoimmune response to AChR is also supported by the observation that anti-AChR antibody titers in MG patients correlated with the degree of thymic hyperplasia, as hyperplastic patients have higher autoantibody titers than those with involuted thymus or thymoma [100]. Moreover, anti-AChR antibody production by thymic lymphocytes from MG patients correlated with in vivo AChR antibody titers and histological thymic abnormalities, with lymphocytes from hyperplastic thymuses being able to produce larger quantities of autoantibodies than those from involuted and thymomatous thymuses [101].

The pathogenic role of the thymus in MG pathogenesis is even reinforced by experiments on severe combined immunodeficiency (SCID) mice grafted with thymic tissue fragments from MG patients. In these mice, human anti-AChR antibodies were detected in serum
1 to 2 weeks after transplantation, proving that the thymus contains all cellular components required for autoantibody production [102].

The evidence that a high proportion of AChR-MG patients undergo true remission after thymectomy $[103,104]$, the fact that AChR antibody titers frequently fall after thymectomy and that the magnitude of this fall correlates with the number of GC B cells in the removed thymus [105], and the observation that the severity of follicular hyperplasia and density of lymphoid infiltrates correlates with improvement after thymectomy [106], again support the pathogenic role of the thymus in AChR-MG [21].

Diffuse hyperplasia (or thymitis) shows histological features similar to those of follicular hyperplasia, with the presence of abundant and diffuse B-cell infiltrates in the thymic parenchyma, but lacks GCs. The involuted thymus that occurs most often in LOMG patients, is very similar to that of age-matched controls in terms of amount of adipose tissue and epithelial space, but the residual islands of medullary parenchyma can present diffuse B-cell infiltrates that in some cases form GCs [89]; this suggests that involuted thymuses are characterized by significant immunological activity.

What drives infiltration of peripheral B-cells and formation of lymphoid aggregates in MG thymus is not fully clear. We demonstrated the overexpression of chemokines in the thymus of MG patients that probably support the recruitment of peripheral cells into the thymus: CXCL13, CCL21, CCL19 and CXCL10 [90,107-109]. We also showed that the hyperplastic MG thymus is the site of active neoangiogenic processes, including the abnormal development of lymphatic vessels and high endothelial venules (HEVs), specialized post-capillary swellings bearing surface chemokines that regulate homing of lymphocytes and dendritic cells in secondary lymphoid organs. Specifically, we demonstrated that CCL21, a chemoattractant for T- and B-cells, is overexpressed in afferent lymphatic endothelial vessels [108]. SDF-1 (also called CXCL12), a chemokine able to recruit monocytes/macrophages, dendritic cells and B-cells is selectively expressed by HEVs of hyperplastic MG thymus [110]. These data suggest a functional role of these chemokines in sustaining the immune cell increase associated with thymic hyperplasia in MG patients.

\subsection{The inflammatory status of MG thymus: the IFN imprinting}

In MG pathogenesis, as the autoimmune sensitization against AChR is observed in the thymus, the role of inflammatory cytokines is crucial. Thymomatous and some LOMG patients present high-titers of neutralizing autoantibodies against IFN-I and IL-12, suggesting an increased expression of these cytokines. The production of these neutralizing antibodies seems directly linked to the tumors as their titers usually increase strikingly when thymomas recur or metastasize; moreover, cells cultured from thymomas spontaneously produce antibodies to IFN- $\alpha$ and/or IL-12 [111,112]. In EOMG patients, a thymic transcriptome analysis has also underlined the inflammatory state of MG thymus and, in particular, the overexpression of numerous proinflammatory cytokines, chemokines and IFN induced-genes that could participate at different levels to host defense and/or disease in response to viral infection [90]. The potential role of IFN subtypes in EOMG is described below.

IFN-II or IFN- $\gamma$ is the unique ligand for a receptor consisting of IFN- $\gamma$ R1 and IFN- $\gamma$ R2 subunits [113]. IFN-II has been implicated in various autoimmune diseases because of its pro-inflammatory properties, in particular its ability to induce HLA class I and II gene expression and to promote Th1 differentiation. The role of IFN-II has been well studied in MG where it can trigger functional disruption of the neuromuscular junction [114]. Attempts to induce EAMG in IFN-II or IFN-II-receptor knock-out mice demonstrate that IFN-II is involved in the generation of a pathogenic anti-AChR humoral immune response and for conferring susceptibility to clinical EAMG to mice $[115,116]$. 
In the thymus, an up-regulation of IFN-II-induced genes is observed and the analysis of the effects of IFN-II on AChR subunit expression in thymic epithelial cell and myoid cell cultures has demonstrated that IFN-II is a strong inducer of AChR subunits and, in particular, of AChR- $\alpha$ [117]. In IFN-II knock-out mice, the absence of IFN-II significantly reduces the expression of AChR- $\alpha$ mRNA in the thymus, while it does not have any effect on AChR- $\alpha$ expression in the muscle [117]. An increased expression of IFN-II that was shown to affect the generation of regulatory $T$ cells could also play a role in MG pathogenesis [118].

IFN-I subtypes are secreted by various cells as an anti-viral defense mechanism. Abnormal production of type I interferon has been associated with multiple autoimmune diseases. The role of IFN-I has not been studied in EAMG models and not so much in human MG pathogenesis. This is probably due to the complexity of the IFN-I family. IFN-I consists of 12 different IFN- $\alpha$ subtypes in addition to one IFN $-\beta$ and IFN- $-\sigma,-\varepsilon,-\tau,-\delta$ and $-\kappa$. All IFN-I subtypes have antiviral properties and bind to a common receptor [113].

The implication of IFN-I in MG has long been suggested, as: a) the development of MG was observed after IFN- $\alpha$ - or $-\beta$-based therapies [72]; b) antibodies against IFN- $\alpha$ were found in some MG patients, mainly those with thymoma [111,119]; and c) thymic transcriptome analysis of different MG patient subgroups revealed a significantly increased expression of IFN-I-induced genes [64,117]. We recently demonstrated a specific overexpression of IFN- $\beta$ in the thymus of MG patients [73]. IFN-I could directly affect thymic epithelial cell behavior but also thymocytes differentiation/activation. A study on PBMCs has demonstrated that a chronic elevation of IFN- $\alpha$ could modify the effector/regulatory $\mathrm{T}$ cells ratio towards effector $\mathrm{T}$ cells and autoimmunity [120]. IFN-I could also alter central tolerance towards $\alpha$-AChR by modulating its expression in thymic epithelial cells [73].

IFN-III subtypes have been described more recently and comprise IFN- $\lambda 1,-\lambda 2$ and $-\lambda 3$, also referred to as IL-29, IL-28A and IL-28B, respectively [113]. These cytokines are induced in response to viral infections and appear to use the same pathways as those of IFN- $\alpha / \beta$ to develop an anti-viral response [121]. They also seem to act primarily on epithelial cells [122]. In our thymic transcriptome study, these cytokines were not spotted on the arrays but we observed an overrepresentation of the 19q13 chromosome region, the loci of the three IFN-III subtypes [90]. Analyzing by real-time PCR their thymic expression, we observed a significant overexpression of IFN- $\lambda 1 / 2$ but not of IFN $-\lambda 3$ in the thymus of MG patients compared to non-MG patients (unpublished data). Their role in MG needs them to be investigated.

The inflammatory environment characteristic of MG thymus, with IFN overexpression, could act at different thymic levels modifying AChR expression, altering self-tolerance, affecting the generation of regulatory $T$ cells, and consequently triggers an autoimmune response towards AChR.

\section{Link between innate immunity and autoimmunity in MG}

Although the adaptive immune system has long been a focus of attention in the study of autoimmunity, innate immune response to infections is increasingly emerging as being central to the pathogenesis of autoimmune diseases. In MG, striking evidence of chronic inflammation and emerging data on persistent viral infections in the thymus of MG patients strongly support the hypothesis that the innate immune system may trigger or favor the autoimmune condition.

\subsection{Overview of the role of innate immunity in autoimmunity}

Innate immune system is the first line of defense against infections. It provides a rapid host defense that precedes the adaptive immunity. The main features of the innate immune response include the following: a) it is nonspecific, being triggered by molecules shared by groups of related pathogens; $b$ ) it is immediate and lacks of memory; and c) it is mediated by germline-encoded receptors, the "so-called" patter recognition receptors (PRRs), that are expressed by the effectors cells of innate immunity, mainly natural killer cells, macrophages and dendritic cells, but also by lymphoid cells and non-lymphoid cells. The adaptive immune response is, instead, characterized by relatively slow response kinetics, memory and specificity [123]. Innate and adaptive immune systems have long been studied and considered as two separate entities. However, it has now become clear that the two systems are closely linked and form a single, highly integrated set of defenses against pathogens, with the innate immune response being able to elicit the adaptive immune response [124]. A major role in innate immunity is played by TLRs, a type of PRRs able to recognize conserved microbial molecules and to initiate MyD88dependent or -independent signaling pathways that lead to inflammatory and antimicrobial innate immune responses. Recognition of microbial products by TLR expressed on dendritic cells triggers activation and functional maturation of these cells into antigenpresenting cells leading to initiation of antigen-specific adaptive immune responses $[124,125]$. In humans, ten functional members of TLR family have been identified, each of them able to recognize specific microbial derived molecular structures (Table 2) [126]. Although the function of TLR-mediated innate responses is to confer selfprotection, several studies, both in experimental settings and in a number of human autoimmune diseases, have indicated that the loss of regulation of TLR signaling, as well as the recognition of self molecules by TLRs, can lead to chronic inflammation and autosensitization, thereby promoting or favoring inflammatory and autoimmune diseases [127]. There is increasing evidence indicating that the TLR-mediated pathways play a role in systemic lupus erythematosus [128], type 1 diabetes [129], rheumathoid arthritis [130] and multiple sclerosis [131]. In regard to multiple sclerosis, recently Tzartos and colleagues [132] provided evidence of the activation of TLR3-mediated innate immune response in active lesions of multiple sclerosis brain overexpressing inflammatory IFN- $\alpha$, where signs of EBV latency were found $[132,133]$ suggesting that EBV-driven innate immune responses might contribute to neuroinflammation in the brain of multiple sclerosis patients.

The contribution of TLRs in autoimmunity can mainly be explained by the ability of these receptors to stimulate maturation of antigenpresenting cells, production of IFN-I and other proinflammatory cytokines, which in turn cause priming of adaptive immune cells, such as autoreactive T-cells [126]. Chronic inflammation is a major feature of target organs in many organ-specific autoimmune diseases and a major contributing factor in the development or maintenance of autoimmunity; it represents a crucial event that leads from TLR activation to autosensitization and autoreactivity. Moreover, there is experimental evidence that, along with antigen binding to the B-cell receptor and CD40 stimulation, TLR stimuli, mainly those mediated by TLR3, 7 and 9 , provide additional costimulatory signals for proliferation, maturation and survival of B-cells, including autoreactive B cells, thus compromising B-cell tolerance [134-136]. In vitro and in vivo studies suggested that persistent activation of nucleic acid-sensing TLRs (i.e. TLR7, 8 and 9) may cause systemic autoimmunity, through stimulation of B-cell activation and autoantibody production [137]. However, a tolerogenic role for TLR9 has recently been described by Miles and colleagues [138]; they reported evidence that TLR9 engagement in B cells in response to DNA complexes expressed by apoptotic cells is essential for maintaining peripheral B-cell tolerance, thus suggesting that the balance between regulatory and inflammatory function of TLR9 may be crucial for avoiding autoimmunity.

TLR stimuli have recently found to influence regulatory T cell function. In a study of Hackl and collaborators [139], in vitro and in vivo activation of dendritic cells by TLR7 ligands reduced regulatory T cell generation and the suppressive function, suggesting that TLR7 
Table 2

TLR expression in the thymus of MG and non-MG patients.

\begin{tabular}{|c|c|c|c|}
\hline TLR & Ligands & Thymic transcriptome study [79] & PCR on thymus \\
\hline TLR1 & Triacyl lipoproteins from bacteria & $\begin{array}{l}\text { Overexpressed only in MG with } \\
\text { thymic hyperplasia }\end{array}$ & nd \\
\hline TLR2 & $\begin{array}{l}\text { Microbial molecules from Gram-positive } \\
\text { and -negative bacteria, mycoplasma and yeast }\end{array}$ & Overexpressed in MG & $\begin{array}{l}\text { Down regulated in MG [133] } \\
\text { Overexpressed in MG (Le Panse, UD) }\end{array}$ \\
\hline TLR3 & dsRNA from viruses & Overexpressed in MG & $\begin{array}{l}\text { Down regulated in MG [133] } \\
\text { Overexpressed in MG [63] }\end{array}$ \\
\hline TLR4 & Lipopolysaccharide from Gram-negative bacteria & nd & Overexpressed in MG [133] \\
\hline TLR5 & Flagellin from Gram-positive and -negative bacteria & No significant change & No significant change [133] \\
\hline TLR6 & Diacyl lipoproteins from bacteria and mycoplasma & nd & nd \\
\hline TLR7 & ssRNA from viruses & No significant change & Overexpressed in MG (Cavalcante, UD) \\
\hline TLR8 & ssRNA from viruses & nd & Overexpressed in MG (Le Panse, UD) \\
\hline TLR9 & $\begin{array}{l}\text { Unmethylated CpG oligonucleotide DNA from } \\
\text { viruses and bacteria }\end{array}$ & nd & Overexpressed in MG (Cavalcante, UD) \\
\hline TLR10 & Unknown & Overexpressed in MG & nd \\
\hline
\end{tabular}

nd $=$ not done; UD = unpublished data.

activation in response to viral infections may compromise tolerance maintenance by regulatory $\mathrm{T}$ cells.

In view of the "pro-autoimmunity" effect of TLRs, therapies targeting TLR pathways, mainly based on the use of TLR antagonists, are currently testing in clinical trials for both systemic and organ-specific autoimmune diseases, including systemic lupus erythematosus, rheumatoid arthritis and multiple sclerosis [131].

\subsection{TLR activation in MG thymus}

The observation of IFN-I and IFN-III overexpression in MG thymus suggests a link of MG to pathogen infection. If numerous studies suggest that TLR activation could be involved in various autoimmune diseases [140,141], few data are available on MG. A recent paper analyzed TLR mRNA expression in PBMCs from MG and non-MG patients, observing in MG a decreased expression for TLR1, TLR6 and TLR10 and an increased expression for TLR2, TLR3, TLR4, TLR5, TLR8, and TLR9. In addition, they found that TLR9 mRNA expression is significantly related to the clinical severity of the disease which suggests that TLR signaling may contribute to MG pathogenesis [142]. The thymus is a common target organ for infectious diseases [143]. Changes regarding TLR expression in MG thymus have been investigated for TLR2, TLR3, TLR4 and TLR5 and a clear increased expression of TLR4 has been observed in the hyperplastic thymus of MG patients [144]. In Table 2, we report the data of TLR mRNA expression in the thymus of MG patients, collected from two MG populations in France and Italy. Different results were obtained regarding TLR2 and TLR3 expression. This might be related to a difference in the level of expression of TLR2 and TLR3 in the control groups (non-MG patients): in the Italian study control thymuses were from babies, whereas in the French study they were from adults. Our unpublished data showed that TLR2 and TLR3 mRNA levels were higher in the thymus of babies than in adults. It is also possible that the observed discrepancy may be due to exposure to different pathogens in the two countries.

Recently, to investigate the potential consequences of pathogen infection on thymus, we analyzed the effects of TLR agonists (from TLR1 to TLR9) on human thymic epithelial cell cultures. We demonstrated that poly(I:C), a synthetic analog of dsRNA, specifically induces thymic overexpression of $\alpha-A C h R$ but no other AChR subunits or tissue-specific antigens. This induction is mediated through TLR3 and protein kinase $\mathrm{R}$ (PKR), and by the release of IFN- $\beta$. Interestingly, we also showed the overexpression in the MG thymus of TLR3, PKR, IRF7, IRF5 and IFN- $\beta$ that are all involved in antiviral responses to dsRNA [73]. In addition, poly(I:C) injections in wild-type mice, but not in IFN-I receptor knockout mice, specifically increased thymic expression of $\alpha$-AChR and, at later time points, induced an anti-AChR autoimmune response characterized by a significant production of serum anti-AChR antibodies, a specific proliferation of B cells and
MG-like clinical signs [73]. This study makes a link between a potential viral etiological mechanism in MG and the specific immune response to AChR.

\subsection{Role of viral infections in thymic MG pathogenesis}

As for other autoimmune diseases, the contribution of pathogen infections to MG pathogenesis has long been suspected. Several mechanisms have been postulated to explain how pathogen infections might trigger autoimmunity [78]. Based on the early theory of "molecular mimicry" [145], that was documented in many animal models of autoimmune diseases, autoreactivity could be the result of an immune response to microbial antigens that is able to activate T-cells crossreacting with self antigens [78]. Another possible mechanism related to infection-induced autoimmunity is referred to as the "bystander effect" that occurs secondary to infection. The initial viral infection induces a localized inflammation of the target organ and triggers an autoantigen sensitization [79]. In recent years, accumulating data indicate that the general activation of the immune system by innate immune components responding to pathogens may be a pivotal mechanism linking infections to autoimmunity. In that way, B-cell activation by infectious agents, such as EBV, bacterial DNA or CpG sequences may also contribute to autoimmunity initiation [134].

Although infectious agents have not been unequivocally demonstrated as triggering factors in MG, some "early" and more recent data, strongly support the idea that pathogens could significantly contribute to MG development and progression. Cases of MG with disease onset occurring immediately after proven infection with measles [146], EBV [147], or co-infection with human immunodeficiency virus (HIV) and human T-lymphotropic virus (HTLV) [148], have been documented. The observation that cross-reactivity may exist between AChR peptides and proteins from herpes simplex [149], Escherichia coli, Proteus vulgaris, and Klebsiella pneumoniae [150] suggested that molecular mimicry could be a mechanism implicated in virus-mediated autoimmunity in MG. Early serological studies aimed at identifying antiviral antibodies in MG serum and trying to correlate viral infections with the disease, produced contrasting results $[151,152]$. However, a recent study of Csuka and collaborators [153] showed that high levels of EBV nuclear antigen (EBNA)-1 antibodies are more common in MG than healthy controls and are particularly associated with EOMG, supporting the hypothesis that, similarly to multiple sclerosis [154], an association between EBV infection and EOMG might exist, highlighting the need to further investigate the role of EBV in EOMG.

Some early attempts to detect or isolate viruses from homogenates or cell suspensions from MG thymuses failed [155,156], but the negative results could well be due to the low sensitivity of the detection techniques or to the procedures of storing and processing the 
thymus tissues, that may not have been optimal compared with those used today. Nevertheless, a study of McGuire and colleagues [157] provided evidence of EBV DNA in thymuses of 2 out of 4 MG patients with thymic hyperplasia and 2 out of 2 patients with thymoma, suggesting a role of EBV in autoimmunity and thymoma development in MG. The inflammatory signature of hyperplastic MG thymus [91] and the increased expression of TLR3 and TLR4 that we observed in some MG thymuses [73,144] are compatible with the hypothesis that viral infections could underlie the intra-thymic MG pathogenesis. By using PCR-based techniques, we investigated the presence of cytomegalovirus, herpes zoster virus, herpes simplex types 1 and 2, eubacteria, respiratory syncytial virus, and enteroviruses - viruses known to activate TLR4 - in MG thymuses positive to TLR4 and identified the presence of poliovirus type 1 (PV) RNA in 4 out of 27 (14.8\%) of MG tissues examined [158]. None of 18 non-myasthenic control thymuses examined was positive to PV RNA. In PV positive cases, we detected plus- and minus-strand PV RNAs and found a linear correlation between their levels, thus indicating persistent PV infection. Immunolocalization of the viral capsid protein of enteroviruses in PV RNA positive MG thymuses revealed the presence of PV in macrophages expressing TLR4, that were disseminated in the thymic parenchyma. The finding of a persistent PV infection in the thymus of some MG patients strongly supported the idea that, in the context of a genetic background predisposing to MG, a persistent or dysregulated TLR4-mediated innate immune response to pathogens invading the thymus could cause or sustain thymic chronic inflammation, thus favoring autosensitization and autoimmunity (Fig. 1). Recently, we provided another important finding strengthening the concept of a viral contribution to MG etiology: the identification of an active EBV infection as dominant features of the thymus of EOMG patients [159]. EBV, a widely diffused B-lymphotropic gamma-herpes virus that infects most of the world population, has been associated with the etiology of several autoimmune diseases, like multiple sclerosis, systemic lupus erythematosus and rheumatoid arthritis [160]. Similarly to the brain of multiple sclerosis patients, in which Serafini and co-workers found multiple signs of active EBV infection [133], we provided evidence for the first time of EBV persistence and reactivation in the thymus of EOMG patients, but not in control thymuses from adult healthy subjects $[159,161]$. This finding supported the idea of a possible common mechanism involving EBV to explain persistent inflammation and autoimmunity perpetuation in autoimmune conditions, as multiple sclerosis and MG, characterized by B-cell activation, lymphoid neogenesis and chronic inflammatory status in the target/affected organs. Thymic EBV signature could also explain dsRNA-signaling pathway activation observed in MG thymus [73]. Indeed, EBV encodes small RNAs (EBER) that trigger TLR3 signaling and induce IFN-I and proinflammatory cytokine expression, similarly to poly(I:C), a synthetic dsRNA [162]. The ability of EBV to infect and transform B-cells, allowing them to evade immune surveillance [160], makes it a prime suspect for chronic infection and inflammation. The concentration of the virus in MG thymus could provide an explanation for how the autoimmune response can be perpetuated in this organ in MG patients, since EBV could activate and immortalize intra-thymic autoantibody-producing cells and sustain chronic inflammation via TLR-mediated pathways [163]. The recruitment of peripheral lymphoid cells in the thymus by inflammatory chemokines could create a "vicious circle" in which new events of autosensitization and EBV infection could sustain and perpetuate the thymic autoimmune response. Whether a pre-existing inflammatory state, of different origin than EBV infection, is responsible for the recruitment of EBVharboring cells in MG thymus and for subsequent EBV reactivation, is unknown. In contrast with our findings, two recent studies reported absence or very low levels of EBV infection in the thymus of EOMG patients $[164,165]$. Different tissue processing and different procedures to detect EBV were used and this could explain the discrepancies in the obtained results [166]. Since EBV search in human tissues may be extremely challenging, technical issues related to tissue storage and processing, and use of more or less sensitive techniques, could be critical to obtain successful results. The use of a combination of techniques, as in situ hybridization, immunohistochemistry and molecular techniques to detect various EBV markers [159,161], applied on optimal stored and processed tissues and with the use of appropriate positive and negative controls, could be a correct approach to further investigate EBV presence in the thymus, as well as in other tissue types. Given the potential therapeutic implications that could have EBV confirmation as pathologic feature of MG thymus, additional studies investigating more deeply the EBV relationship with MG are worthy to be done to provide new insights.

\section{Conclusions}

MG is a complex autoantibody-mediated neurological disease involving both genetic and environmental risk factors. Different MG subtypes, usually defined by autoantibody signature, disease severity, age at onset and thymic involvement, exist and could differ in etiology. AChR-MG occurring in EOMG patients and presenting with thymic hyperplasia is the most common, and also the best characterized, subtype of MG. An intra-thymic pathogenic link between innate immunity and autoimmunity can be postulated for AChR-MG: the observation of an IFN and TLR signature in the hyperplastic MG thymus, along with data showing that inflammatory cytokines can increase the expression levels of $\alpha$-AChR in thymic epithelial cells and myoid cells, suggest the hypothesis that, in the context of a genetic predisposing background, intra-thymic infection events might contribute to the specific immune response to $A C h R$, by eliciting altered innate immune responses that lead to anti-AChR autosensitization and adaptive autoimmune response (Fig. 1). The fact that dsRNAsignaling activation can induce thymic changes related to MG and even trigger a specific anti-AChR response in mice speaks for a viral etiological mechanism in MG. Moreover, our recent finding of an active EBV infection in B-cells/plasma cells of MG thymus provides an explanation on how the autoimmune response can be perpetuated in this organ, since EBV is potentially able to immortalize thymic autoreactive $\mathrm{B}$ cells that then can leave the thymus and perpetuate autoreactivity in periphery. EBV itself could sustain, alone or together with other pathogens (co-infection events), chronic inflammation and dysregulated TLR activation in MG thymus. Further investigation is needed to dissect the mechanisms postulated in our proposed model.

\section{Take-home messages}

- Variation in autoantibody status is associated with different MG clinical phenotypes.

- HLA loci are the main genetic factors implicated in MG susceptibility. - The thymus is the prime site of autosensitization to AChR in MG.

- TLR-mediated innate immune response is involved in the thymic etiology of MG.

- Active EBV infection was found in the thymus of MG patients.

\section{Financial support}

This work was supported by grants from the "Association Francaise Contre les Myopathies" (AFM), the European Commission (FIGHT-MG, contract \# FP7 HEALTH-2009-242-210), and Italian Ministry of Health, year 2012 (annual research funding).

\section{Conflicts of interest}

P.C., P.C., R.L.P and S.B.A have no conflict of interest.

R.M. has served on a scientific advisory board for GlaxoSmithKline, Alexion, and Bio-Marin and has received funding for travel and 


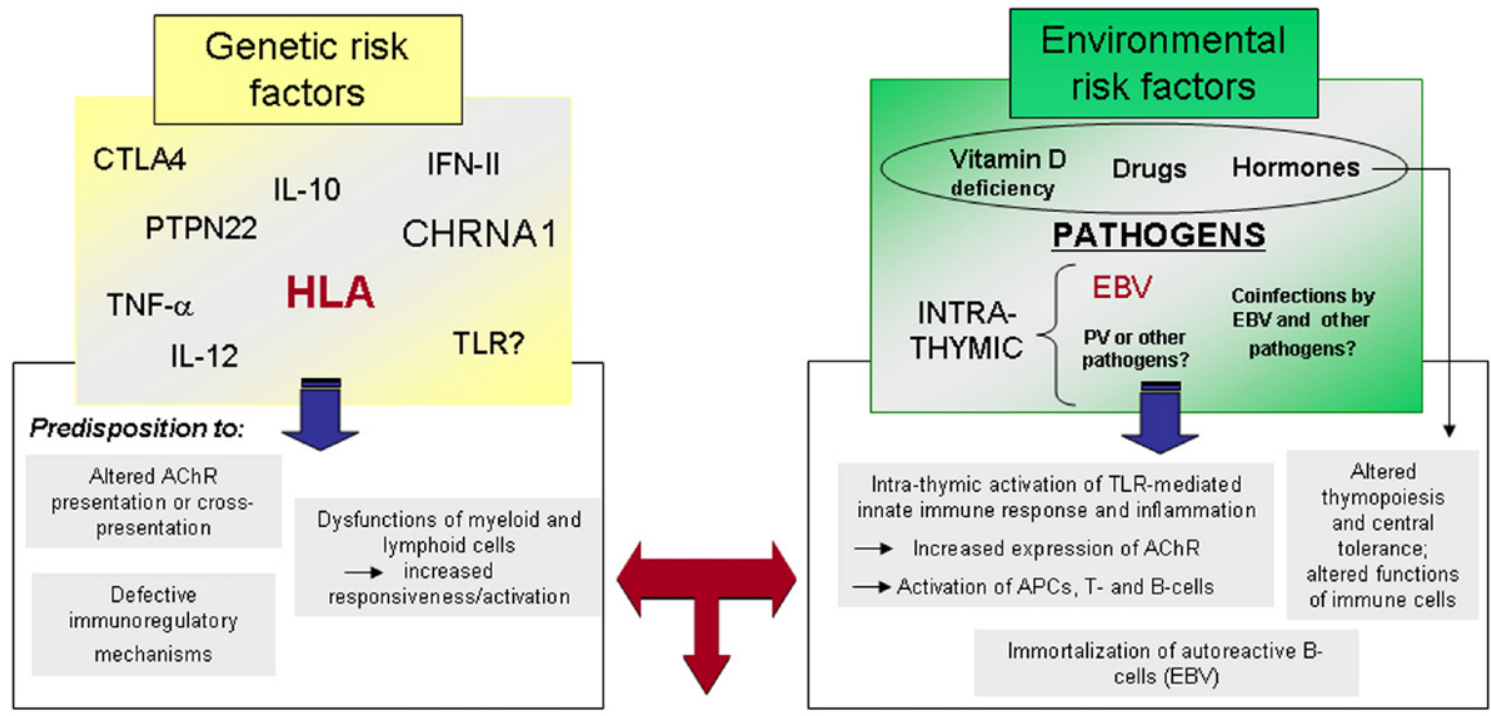

Autoimmune response against $\mathrm{AChR}$ within the thymus

Perpetuation of autoimmunity in periphery

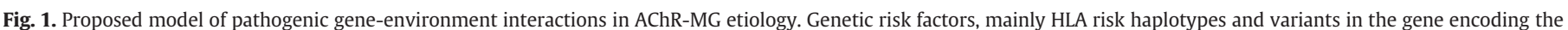

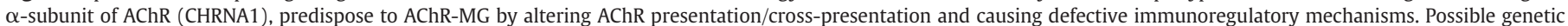

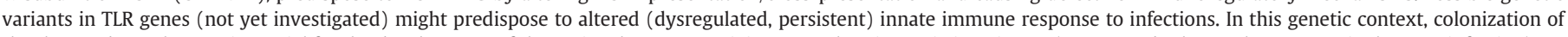

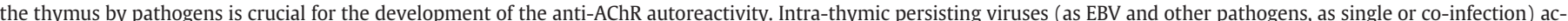

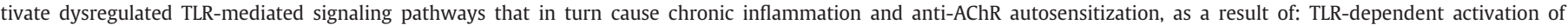

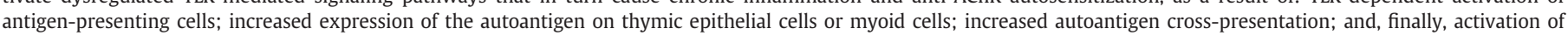

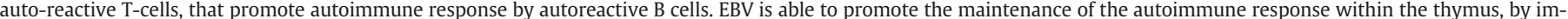

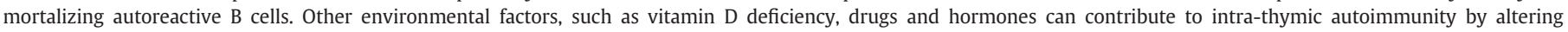
thymopoiesis and immune cell function, thus favoring central tolerance disruption.

speaker honoraria from Sanofi-Aventis, Merck-Serono and MEDA Pharmaceuticals Inc. Inc.

P.B. has received a speaker honorarium from MEDA Pharmaceuticals

\section{References}

[1] Vincent A. Unravelling the pathogenesis of myasthenia gravis. Nat Rev Immunol 2002;2:797-804.

[2] Leite MI, Jacob S, Viegas S, Cossins J, Clover L, Morgan BP, et al. IgG1 antibodies to acetylcholine receptors in 'seronegative' myasthenia gravis. Brain 2008;131: 1940-52.

[3] Jacob S, Viegas S, Leite MI, Webster R, Cossins J, Kennett R, et al. Presence and pathogenic relevance of antibodies to clustered acetylcholine receptor in ocular and generalized myasthenia gravis. Arch Neurol 2012;69:994-1001.

[4] Hoch W, McConville J, Helms S, Newsom-Davis J, Melms A, Vincent A. Autoantibodies to the receptor tyrosine kinase MuSK in patients with myasthenia gravis without acetylcholine receptor antibodies. Nat Med 2001:7:365-8.

[5] Evoli A, Tonali PA, Padua L, Monaco ML, Scuderi F, Batocchi AP, et al. Clinical correlates with anti-MuSK antibodies in generalized seronegative myasthenia gravis. Brain 2003;126:2304-11.

[6] Sanders DB, El-Salem K, Massey JM, McConville J, Vincent A. Clinical aspects of MuSK antibody positive seronegative MG. Neurology 2003;60:1978-80.

[7] McConville J, Farrugia ME, Beeson D, Kishore U, Metcalfe R, Newsom-Davis ], et al. Detection and characterization of MuSK antibodies in seronegative myasthenia gravis. Ann Neurol 2004;55:580-4.

[8] Evoli A, Padua L. Diagnosis and therapy of myasthenia gravis with antibodies to muscle-specific kinase.Autoimmun Rev 2013;12:931-5 (this issue).

[9] Mori S, Shigemoto K. Mechanisms associated with the pathogenicity of antibodies against muscle-specific kinase in myasthenia gravis.Autoimmun Rev 2013;12:912-7 (this issue)

[10] Zisimopoulou P, Brenner T, Trakas N, Tzartos SJ. Serological diagnostics in myasthenia gravis based on novel assays and recently identified antigens.Autoimmun Rev 2013;12:924-30 (this issue).
[11] Zhang B, Tzartos JS, Belimezi M, Ragheb S, Bealmear B, Lewis RA, et al. Autoantibodies to lipoprotein-related protein 4 in patients with double-seronegative myasthenia gravis. Arch Neurol 2012;69:445-51.

[12] Pevzner A, Schoser B, Peters K, Cosma NC, Karakatsani A, Schalke B, et al. Anti-LRP4 autoantibodies in AChR- and MuSK-antibody-negative myasthenia gravis. J Neurol 2012;259:427-35.

[13] Higuchi O, Hamuro J, Motomura M, Yamanashi Y. Autoantibodies to low-density lipoprotein receptor-related protein 4 in myasthenia gravis. Ann Neurol 2011;69:418-22.

[14] Mantegazza R, Baggi F, Antozzi C, Confalonieri P, Morandi L, Bernasconi P, et al. Myasthenia gravis (MG): epidemiological data and prognostic factors. Ann N Y Acad Sci 2003;998:413-23.

[15] Heldal AT, Owe JF, Gilhus NE, Romi F. Seropositive myasthenia gravis: a nationwide epidemiologic study. Neurology 2009;73:150-1.

[16] Aragones JM, Bolibar I, Bonfill X, Bufill E, Mummany A, Alonso F, et al. Myasthenia gravis: a higher than expected incidence in the elderly. Neurology 2003;60:1024-6.

[17] Meyer A, Levy Y. Geoepidemiology of myasthenia gravis. [corrected] Autoimmun Rev 2010;9:A383-6.

[18] Drachman DB, Adams RN, Josifek LF, Self SG. Functional activities of autoantibodies to acetylcholine receptors and the clinical severity of myasthenia gravis. N Engl J Med 1982;307:769-75.

[19] Vincent A, McConville J, Farrugia ME, Newsom-Davis J. Seronegative myasthenia gravis. Semin Neurol 2004;24:125-33.

[20] Müller-Hermelink HK, Marx A, Geuder KI, Kirchner T. Thymus. In: Damjanov I, Linder J, editors. Anderson's Pathology. Saint Louis: Mosby; 1996. p. 1218-43.

[21] Berrih-Aknin S, Le Ragheb S, Panse R, Lisak RP. Ectopic germinal centers, BAFF and anti-B cell therapy in myasthenia gravis.Autoimmun Rev 2013;12:885-93 (this issue).

[22] Patrick J, Lindstrom J. Autoimmune response to acetylcholine receptor. Science 1973;180:871-2.

[23] Dalakas MC. Novel future therapeutic options in Myasthenia Gravis.Autoimmun Rev 2013;12:936-41 (this issue).

[24] Murphy J, Murphy SF. Myasthenia gravis in identical twins. Neurology 1986;36: 78-80.

[25] Vandiedonck C, Giraud M, Garchon HJ. Genetics of autoimmune myasthenia gravis: the multifaceted contribution of the HLA complex. J Autoimmun 2005;25(Suppl.):6-11. 
[26] Degli-Esposti MA, Andreas A, Christiansen FT, Schalke B, Albert E, Dawkins RL. An approach to the localization of the susceptibility genes for generalized myasthenia gravis by mapping recombinant ancestral haplotypes. Immunogenetics 1992;35:355-64.

[27] Perricone C, Ceccarelli F, Valesini G. An overview on the genetic of rheumatoid arthritis: a never-ending story. Autoimmun Rev 2011;10:599-608.

[28] Borchers AT, Naguwa SM, Shoenfeld Y, Gershwin ME. The geoepidemiology of systemic lupus erythematosus. Autoimmun Rev 2010;9:A277-87.

[29] Christensen PB, Jensen TS, Tsiropoulos I, Sorensen T, Kjaer M, Hojer-Pedersen E, et al. Associated autoimmune diseases in myasthenia gravis. A population-based study. Acta Neurol Scand 1995;91:192-5.

[30] Baggi F, Antozzi C, Andreetta F, Confalonieri P, Ciusani E, Begovich AB, et al. Identification of a novel HLA class II association with DQB1*0502 in an Italian myasthenic population. Ann N Y Acad Sci 1998;841:355-9.

[31] Deitiker PR, Oshima M, Smith RG, Mosier D, Atassi MZ. Association with HLA DQ of early onset myasthenia gravis in Southeast Texas region of the United States. Int J Immunogenet 2011;38:55-62.

[32] Lio D, Candore G, Romano GC, D'Anna C, Gervasi F, Di Lorenzo G, et al. Modification of cytokine patterns in subjects bearing the HLA-B8, DR3 phenotype: implications for autoimmunity. Cytokines Cell Mol Ther 1997;3:217-24.

[33] Maniaol AH, Elsais A, Lorentzen AR, Owe JF, Viken MK, Saether H, et al. Late onset myasthenia gravis is associated with HLA DRB1*15:01 in the Norwegian population. PLoS One 2012;7:e36603.

[34] Niks EH, Kuks JB, Roep BO, Haasnoot GW, Verduijn W, Ballieux BE, et al. Strong association of MuSK antibody-positive myasthenia gravis and HLA-DR14-DQ5. Neurology 2006;66:1772-4.

[35] Bartoccioni E, Scuderi F, Augugliaro A, Chiatamone Ranieri S, Sauchelli D, Alboino $\mathrm{P}$, et al. HLA class II allele analysis in MuSK-positive myasthenia gravis suggests a role for DQ5. Neurology 2009;72:195-7.

[36] Vieira ML, Caillat-Zucman S, Gajdos P, Cohen-Kaminsky S, Casteur A, Bach JF. Identification by genomic typing of non-DR3 HLA class II genes associated with myasthenia gravis. J Neuroimmunol 1993;47:115-22.

[37] Vandiedonck C, Raffoux C, Eymard B, Tranchant C, Dulmet E, Krumeich S, et al. Association of HLA-A in autoimmune myasthenia gravis with thymoma. J Neuroimmunol 2009;210:120-3.

[38] Yang H, Hao J, Peng X, Simard AR, Zhang M, Xie Y, et al. The association of HLA-DQA1*0401 and DQB1*0604 with thymomatous myasthenia gravis in northern Chinese patients. J Neurol Sci 2012;312:57-61.

[39] Skeie GO, Pandey JP, Aarli JA, Gilhus NE. TNFA and TNFB polymorphisms in myasthenia gravis. Arch Neurol 1999;56:457-61.

[40] Huang DR, Pirskanen R, Matell G, Lefvert AK. Tumour necrosis factor-alpha polymorphism and secretion in myasthenia gravis. J Neuroimmunol 1999;94:165-71.

[41] Wang HB, Li H, Shi FD, Chambers BJ, Link H, Ljunggren HG. Tumor necrosis factor receptor- 1 is critically involved in the development of experimental autoimmune myasthenia gravis. Int Immunol 2000;12:1381-8.

[42] Wang XB, Pirskanen R, Giscombe R, Lefvert AK. Two SNPs in the promoter region of the CTLA- 4 gene affect binding of transcription factors and are associated with human myasthenia gravis. J Intern Med 2008;263:61-9.

[43] Yilmaz V, Tutuncu Y, Baris Hasbal N, Parman Y, Serdaroglu P, Deymeer F, et al. Polymorphisms of interferon-gamma, interleukin-10, and interleukin-12 genes in myasthenia gravis. Hum Immunol 2007;68:544-9.

[44] Burn GL, Svensson L, Sanchez-Blanco C, Saini M, Cope AP. Why is PTPN22 a good candidate susceptibility gene for autoimmune disease? FEBS Lett 2011:585:3689-98.

[45] Giraud M, Vandiedonck C, Garchon HJ. Genetic factors in autoimmune myasthenia gravis. Ann N Y Acad Sci 2008;1132:180-92.

[46] Gregersen PK, Lee HS, Batliwalla F, Begovich AB. PTPN22: setting thresholds for autoimmunity. Semin Immunol 2006;18:214-23.

[47] Gianchecchi E, Palombi M, Fierabracci A. The putative role of the C1858T polymorphism of protein tyrosine phosphatase PTPN22 gene in autoimmunity.Autoimmun Rev 2012 Dec 20 [pii: S1568-9972(12)00294-7. doi: http://dx.doi.org/10.1016/j. autrev.2012.12.003. [Epub ahead of print]].

[48] Menard L, Saadoun D, Isnardi I, Ng YS, Meyers G, Massad C, et al. The PTPN22 allele encoding an R620W variant interferes with the removal of developing autoreactive B cells in humans. J Clin Invest 2011;121:3635-44.

[49] Zhang J, Zahir N, Jiang Q, Miliotis H, Heyraud S, Meng X, et al. The autoimmune disease-associated PTPN22 variant promotes calpain-mediated Lyp/Pep degradation associated with lymphocyte and dendritic cell hyperresponsiveness. Nat Genet 2011;43:902-7.

[50] Vandiedonck C, Capdevielle C, Giraud M, Krumeich S, Jais JP, Eymard B, et al. Association of the PTPN22*R620W polymorphism with autoimmune myasthenia gravis. Ann Neurol 2006;59:404-7.

[51] Provenzano C, Ricciardi R, Scuderi F, Maiuri MT, Maestri M, La Carpia F, et al. PTPN22 and myasthenia gravis: replication in an Italian population and meta-analysis of literature data. Neuromuscul Disord 2012;22:131-8.

[52] Chuang WY, Strobel P, Belharazem D, Rieckmann P, Toyka KV, Nix W, et al. The PTPN22gain-of-function $+1858 \mathrm{~T}(+)$ genotypes correlate with low IL-2 expression in thymomas and predispose to myasthenia gravis. Genes Immun 2009;10:667-72.

[53] Giraud M, Taubert R, Vandiedonck C, Ke X, Levi-Strauss M, Pagani F, et al. An IRF8-binding promoter variant and AIRE control CHRNA1 promiscuous expression in thymus. Nature 2007;448:934-7.

[54] Lettre G, Rioux JD. Autoimmune diseases: insights from genome-wide association studies. Hum Mol Genet 2008;17:R116-21.

[55] Hystad ME, Myklebust JH, Bo TH, Sivertsen EA, Rian E, Forfang L, et al. Characterization of early stages of human B cell development by gene expression profiling. J Immunol 2007;179:3662-71.
[56] Cheung YH, Watkinson J, Anastassiou D. Conditional meta-analysis stratifying on detailed HLA genotypes identifies a novel type 1 diabetes locus around TCF19 in the MHC. Hum Genet 2011;129:161-76.

[57] Zhang J, Chen Y, Shao Y, Wu Q, Guan M, Zhang W, et al. Identification of TNIP1 polymorphisms by high resolution melting analysis with unlabelled probe: association with systemic lupus erythematosus. Autoimmun Dis 2012;2012: 265823.

[58] Bowes J, Orozco G, Flynn E, Ho P, Brier R, Marzo-Ortega H, et al. Confirmation of TNIP1 and IL23A as susceptibility loci for psoriatic arthritis. Ann Rheum Dis 2011;70:1641-4.

[59] Ramirez VP, Gurevich I, Aneskievich BJ. Emerging roles for TNIP1 in regulating post-receptor signaling. Cytokine Growth Factor Rev 2012;23:109-18.

[60] Nanda SK, Venigalla RK, Ordureau A, Patterson-Kane JC, Powell DW, Toth R, et al Polyubiquitin binding to ABIN1 is required to prevent autoimmunity. J Exp Med 2011;208:1215-28.

[61] Landoure G, Knight MA, Stanescu H, Taye AA, Shi Y, Diallo O, et al. A candidate gene for autoimmune myasthenia gravis. Neurology 2012;79:342-7.

[62] Anaya J-M. Common mechanisms of autoimmune diseases (the autoimmune tautology). Autoimmun Rev 2012;11:781-4.

[63] Nussinovitch U, Shoenfeld Y. The role of gender and organ specific autoimmunity. Autoimmun Rev 2012;11:A377-85.

[64] Le Panse R, Cizeron-Clairac G, Cuvelier M, Truffault F, Bismuth J, Nancy P, et al. Regulatory and pathogenic mechanisms in human autoimmune myasthenia gravis. Ann N Y Acad Sci 2008;1132:135-42.

[65] Oertelt-Prigione $S$. The influence of sex and gender on the immune response. Autoimmun Rev 2012;11:A479-85.

[66] Delpy L, Douin-Echinard V, Garidou L, Bruand C, Saoudi A, Guery JC. Estrogen enhances susceptibility to experimental autoimmune myasthenia gravis by promoting type 1-polarized immune responses. J Immunol 2005;175:5050-7.

[67] Kawashima I, Seiki K, Sakabe K, Ihara S, Akatsuka A, Katsumata Y. Localization of estrogen receptors and estrogen receptor-mRNA in female mouse thymus. Thymus 1992;20:115-21.

[68] Nancy P, Berrih-Aknin S. Differential estrogen receptor expression in autoimmune myasthenia gravis. Endocrinology 2005;146:2345-53.

[69] Selmi C, Brunetta E, Raimondo M, Meroni P. The X chromosome and the sex ratio of autoimmunity. Autoimmun Rev 2012;11:A532-7.

[70] Penn AS, Low BW, Jaffe IA, Luo L, Jacques JJ. Drug-induced autoimmune myasthenia gravis. Ann N Y Acad Sci 1998;841:433-49.

[71] Poulas K, Koutsouraki E, Kordas G, Kokla A, Tzartos SJ. Anti-MuSK- and anti-AChR-positive myasthenia gravis induced by D-penicillamine. J Neuroimmunol 2012;250:94-8.

[72] Stubgen JP. Interferon alpha and neuromuscular disorders. J Neuroimmunol 2009;207:3-17.

[73] Cufi P, Dragin N, Weiss JM, Martinez-Martinez P, Roussin R, Berrih Aknin S, et al. Implication of dsRNA signaling in the etiology of autoimmune myasthenia gravis. Ann Neurol 2013;73:281-93.

[74] Bogdanos DP, Smyk DS, Invernizzi P, Rigopoulou EI, Blank M, Pouria S, et al Infectome: a platform to trace infectious triggers of autoimmunity. Autoimmun Rev 2012. doi:10.1016/j.autrev.2012.12.005.

[75] Askmark H, Haggard L, Nygren I, Punga AR. Vitamin D deficiency in patients with myasthenia gravis and improvement of fatigue after supplementation of vitamin D3: a pilot study. Eur J Neurol 2012;19:1554-60.

[76] Simon KC, Munger KL, Ascherio A. Vitamin D and multiple sclerosis: epidemiology, immunology, and genetics. Curr Opin Neurol 2012;25:246-51.

[77] Antico A, Tampoia M, Tozzoli R, Bizzaro N. Can supplementation with vitamin D reduce the risk or modify the course of autoimmune diseases? A systematic review of the literature. Autoimmun Rev 2012;12:127-36.

[78] Munz C, Lunemann JD, Getts MT, Miller SD. Antiviral immune responses: triggers of or triggered by autoimmunity? Nat Rev Immunol 2009;9:246-58.

[79] Bach JF. Infections and autoimmune diseases. J Autoimmun 2005;25 Suppl.: 74-80.

[80] Temajo NO, Howard N. The viral enterprises in autoimmunity: conversion of target cells into de novo APCs is the presage to autoimmunity. Autoimmun Rev 2012;11:653-8

[81] Leite MI, Strobel P, Jones M, Micklem K, Moritz R, Gold R, et al. Fewer thymic changes in MuSK antibody-positive than in MuSK antibody-negative MG. Ann Neurol 2005;57:444-8.

[82] Lauriola L, Ranelletti F, Maggiano N, Guerriero M, Punzi C, Marsili F, et al. Thymus changes in anti-MuSK-positive and -negative myasthenia gravis. Neurology 2005;64:536-8.

[83] Marx A, Willcox N, Leite MI, Chuang WY, Schalke B, Nix W, et al. Thymoma and paraneoplastic myasthenia gravis. Autoimmunity 2010;43:413-27.

[84] Rosai J, Sobin LH. Histological typing of tumors of the thymus. In: W.H. Organization, editor. International Histological Classification of Tumors. New York: Springer; 1999.

[85] Maggi L, Andreetta F, Antozzi C, Baggi F, Bernasconi P, Cavalcante P, et al Thymoma-associated myasthenia gravis: outcome, clinical and pathological correlations in 197 patients on a 20-year experience. J Neuroimmunol 2008;201-202: 237-44.

[86] Strobel P, Chuang WY, Chuvpilo S, Zettl A, Katzenberger T, Kalbacher H, et al Common cellular and diverse genetic basis of thymoma-associated myasthenia gravis: role of MHC class II and AIRE genes and genetic polymorphisms. Ann N Y Acad Sci 2008;1132:143-56.

[87] Savino W, Manganella G, Verley JM, Wolff A, Berrih S, Levasseur P, et al Thymoma epithelial cells secrete thymic hormone but do not express class II antigens of the major histocompatibility complex. J Clin Invest 1985;76:1140-6. 
[88] Scarpino S, Di Napoli A, Stoppacciaro A, Antonelli M, Pilozzi E, Chiarle R, et al. Expression of autoimmune regulator gene (AIRE) and T regulatory cells in human thymomas. Clin Exp Immunol 2007;149:504-12.

[89] Cavalcante P, Le Panse R, Berrih-Aknin S, Maggi L, Antozzi C, Baggi F, et al. The thymus in myasthenia gravis: site of "innate autoimmunity"? Muscle Nerve 2011;44:467-84.

[90] Le Panse R, Cizeron-Clairac G, Bismuth J, Berrih Aknin S. Microarrays reveal distinct gene signatures in the thymus of seropositive and seronegative myasthenia gravis patients and the role of CCL21 in thymic hyperplasia. J Immunol 2006; 177:7868-79

[91] Cizeron-Clairac G, Le Panse R, Frenkian-Cuvelier M, Méraouna A, Truffault F, Bismuth J, et al. Thymus and myasthenia gravis: what can we learn from DNA microarrays? J Neuroimmunol 2008;201-202:57-63.

[92] Sims GP, Shiono H, Willcox N, Stott DI. Somatic hypermutation and selection of B cells in thymic germinal centers responding to acetylcholine receptor in myasthenia gravis. J Immunol 2001;167:1935-44.

[93] McLachlan SM, Nicholson LV, Venables G, Mastalgia FL, Bates D, Smith BR, et al. Acetylcholine receptor antibody synthesis in lymphocyte cultures. J Clin Lab Immunol 1981;5:137-42.

[94] Schluep M, Willcox N, Vincent A, Dhoot GK, Newsom-Davis J. Acetylcholine receptors in human thymic myoid cells in situ: an immunohistological study Ann Neurol 1987;22:212-22.

[95] Mesnard-Rouiller L, Bismuth J, Wakkach A, Poëa-Guyon S, Berrih-Aknin S. Thymic myoid cells express high levels of muscle genes. J Neuroimmunol 2004;148:97-105.

[96] Wakkach A, Guyon T, Bruand C, Tzartos S, Cohen-Kaminsky S, Berrih-Aknin S. Expression of acetylcholine receptor genes in human thymic epithelial cells: implications for myasthenia gravis. J Immunol 1996;157:3752-60.

[97] Leite MI, Jones M, Strobel P, Marx A, Gold R, Niks E, et al. Myasthenia gravis thymus: complement vulnerability of epithelial and myoid cells, complement attack on them, and correlations with autoantibody status. Am J Pathol 2007;171: 893-905.

[98] Melms A, Schalke BC, Kirchner T, Müller-Hermelink HK, Albert E, Wekerle H. Thymus in myasthenia gravis. Isolation of T-lymphocyte lines specific for the nicotinic acetylcholine receptor from thymuses of myasthenic patients. J Clin Invest 1988;81:902-8.

[99] Hill ME, Shiono H, Newsom-Davis J, Willcox N. The myasthenia gravis thymus: a rare source of human autoantibody-secreting plasma cells for testing potential therapeutics. J Neuroimmunol 2008;201-202:50-6.

[100] Berrih-Aknin S, Morel E, Raimond F, Safar D, Gaud C, Binet J, et al. The role of the thymus in myasthenia gravis: immunohistological and immunological studies in 115 cases. Ann N Y Acad Sci 1987;505:50-70.

[101] Safar D, Berrih-Aknin S, Morel E. In vitro anti-acetylcholine receptor antibody synthesis by myasthenia gravis patient lymphocytes: correlations with thymic histology and thymic epithelial-cell interactions. J Clin Immunol 1987;7:225-34

[102] Schonbeck S, Padberg F, Hohlfeld R, Wekerle H. Transplantation of thymic autoimmune microenvironment to severe combined immunodeficiency mice. A new model of myasthenia gravis. J Clin Invest 1992;90:245-50.

[103] Mantegazza R, Baggi F, Bernasconi P, Antozzi C, Confalonieri P, Novellino L, et al. Video-assisted thoracoscopic extended thymectomy and extended transsterna thymectomy ( $\mathrm{T}-3 \mathrm{~b})$ in non-thymomatous myasthenia gravis patients: remission after 6 years of follow-up. J Neurol Sci 2003;212:31-6.

104] Gronseth GS, Barohn RJ. Practice parameter: thymectomy for autoimmune myasthenia gravis (an evidence-based review): report of the Quality Standards Subcommittee of the American Academy of Neurology. Neurology 2000;55:7-15.

[105] Okumura M, Ohta M, Takeuchi Y, Shiono H, Inoue M, Fukuhara K, et al. The immunologic role of thymectomy in the treatment of myasthenia gravis: implication of thymus-associated B-lymphocyte subset in reduction of the antiacetylcholine receptor antibody titer. J Thorac Cardiovasc Surg 2003;126: 1922-8.

[106] Mori T, Nomori H, Ikeda K, Kobayashi H, Iwatani K, Kobayashi T. The distribution of parenchyma, follicles, and lymphocyte subsets in thymus of patients with myasthenia gravis, with special reference to remission after thymectomy. J Thorac Cardiovasc Surg 2007;133:364-8.

[107] Méraouna A, Cizeron-Clairac G, Le Panse R, Bismuth J, Truffault F, Talaksen C et al. The chemokine CXCL13 is a key molecule in autoimmune myasthenia gravis. Blood 2006;108:432-40.

[108] Berrih-Aknin S, Ruhlmann N, Bismuth J, Cizeron-Clairac G, Zelman E, Shachar I, et al. CCL21 overexpressed on lymphatic vessels drives thymic hyperplasia in myasthenia. Ann Neurol 2009;66:521-31.

[109] Feferman T, Maiti PK, Berrih-Aknin S, Bismuth J, Bidault J, Fuchs S, et al. Overexpression of IFN-induced protein 10 and its receptor CXCR3 in myasthenia gravis. J Immunol 2005;174:5324-31.

[110] Weiss JM, Cufi P, Bismuth J, Eymard B, Fadel E, Berrih-Aknin S, et al. SDF-1/ CXCL12 recruits B cells and antigen-presenting cells to the thymus of autoimmune myasthenia gravis patients. Immunobiology 2013;218:373-81.

[111] Meager A, Wadhwa M, Dilger P, Bird C, Thorpe R, Newsom-Davis J, et al. Anti-cytokine autoantibodies in autoimmunity: preponderance of neutralizing autoantibodies against interferon-alpha, interferon-omega and interleukin-12 in patients with thymoma and/or myasthenia gravis. Clin Exp Immunol 2003;132:128-36.

[112] Willcox N, Leite MI, Kadota Y, Jones M, Meager A, Subrahmanyam P, et al Autoimmunizing mechanisms in thymoma and thymus. Ann N Y Acad Sci 2008;1132:163-73.

[113] de Weerd NA, Nguyen T. The interferons and their receptors-distribution and regulation. Immunol Cell Biol 2012;90:483-91.
[114] Gu D, Wogensen L, Calcutt NA, Xia C, Zhu S, Merlie JP, et al. Myasthenia gravis-like syndrome induced by expression of interferon gamma in the neuromuscular junction. J Exp Med 1995;181:547-57.

[115] Balasa B, Deng C, Lee J, Bradley LM, Dalton DK, Christadoss P, et al. Interferon gamma (IFN-gamma) is necessary for the genesis of acetylcholine receptorinduced clinical experimental autoimmune myasthenia gravis in mice. J Exp Med 1997; 186:385-91.

[116] Zhang GX, Xiao BG, Bai XF, van der Meide PH, Orn A, Link H. Mice with IFN-gamma receptor deficiency are less susceptible to experimental autoimmune myasthenia gravis. J Immunol 1999;162:3775-81.

[117] Poëa-Guyon S, Christadoss P, Le Panse R, Guyon T, De Baets M, Wakkach A, et al. Effects of cytokines on acetylcholine receptor expression: implications for myasthenia gravis. J Immunol 2005;174:5941-9.

[118] Chang JH, Kim YJ, Han SH, Kang CY. IFN-gamma-STAT1 signal regulates the differentiation of inducible Treg: potential role for ROS-mediated apoptosis. Eur J Immunol 2009;39:1241-51.

[119] Meloni A, Furcas M, Cetani F, Marcocci C, Falorni A, Perniola R, et al. Autoantibodies against type I interferons as an additional diagnostic criterion for autoimmune polyendocrine syndrome type I. J Clin Endocrinol Metab 2008;93:4389-97.

[120] Golding A, Rosen A, Petri M, Akhter E, Andrade F. Interferon-alpha regulates the dynamic balance between human activated regulatory and effector T cells: implications for antiviral and autoimmune responses. Immunology 2008;131: 107-17.

[121] Onoguchi K, Yoneyama M, Takemura A, Akira S, Taniguchi T, Namiki H, et al. Viral infections activate types I and III interferon genes through a common mechanism. J Biol Chem 2007;282:7576-81.

[122] Sommereyns C, Paul S, Staeheli P, Michiels T. IFN-lambda (IFN-lambda) is expressed in a tissue-dependent fashion and primarily acts on epithelial cells in vivo. PLoS Pathog 2008;4:e1000017.

[123] Janeway CA, Travers P, Walport M, Capra JD. Principals of innate and adaptive immunity. In: Janeway CA, Travers P, editors. Immunobiology: the Immune System in Health and Disease. New York: Garland Sci; 2001. p. 11-20.

[124] Hoebe K, Janssen E, Beutler B. The interface between innate and adaptive immunity. Nat Immunol 2004;5:971-4.

[125] Medzhitov R. Toll-like receptors and innate immunity. Nat Rev Immunol 2001;1: $135-45$.

[126] Kawai T, Akira S. The role of pattern-recognition receptors in innate immunity: update on Toll-like receptors. Nat Immunol 2010;11:373-84

[127] Hurst J, von Landenberg P. Toll-like receptors and autoimmunity. Autoimmun Rev 2008;7:204-8.

[128] Pisetsky DS. The role of innate immunity in the induction of autoimmunity. Autoimmun Rev 2008;8:69-72.

[129] Lien E, Zipris D. The role of Toll-like receptor pathways in the mechanism of type 1 diabetes. Curr Mol Med 2009;9:52-68.

[130] Shotorbani SS, Su ZL, Xu HX. Toll-like receptors are potential therapeutic targets in rheumatoid arthritis. World J Biol Chem 2011;2:167-72.

[131] Gambuzza M, Licata N, Palella E, Celi D, Foti Cuzzola V, Italiano D, et al. Targeting Toll-like receptors: emerging therapeutics for multiple sclerosis management. J Neuroimmunol 2011;239:1-12.

[132] Tzartos JS, Khan G, Vossenkamper A, Cruz-Sadaba M, Lonardi S, Sefia E, et al. Association of innate immune activation with latent Epstein-Barr virus in active MS lesions. Neurology 2012;78:15-23.

[133] Serafini B, Rosicarelli B, Franciotta D, Magliozzi R, Reynolds R, Cinque P, et al. Dysregulated Epstein-Barr virus infection in the multiple sclerosis brain. J Exp Med 2007;204:2899-912.

[134] Crampton SP, Voynova E, Bolland S. Innate pathways to B-cell activation and tolerance. Ann N Y Acad Sci 2010;1183:58-68.

[135] Green NM, Moody KS, Debatis M, Marshak-Rothstein A. Activation of autoreactive B cells by endogenous TLR7 and TLR3 RNA ligands. J Biol Chem 2012;287:39789-99.

[136] Meyer-Bahlburg A, Rawlings DJ. B cell autonomous TLR signaling and autoimmunity. Autoimmun Rev 2008;7:313-6.

[137] Green NM, Marshak-Rothstein A. Toll-like receptor driven B cell activation in the induction of systemic autoimmunity. Semin Immunol 2011;23:106-12.

[138] Miles K, Heaney J, Sibinska Z, Salter D, Savill J, Gray D, et al. A tolerogenic role for Toll-like receptor 9 is revealed by B-cell interaction with DNA complexes expressed on apoptotic cells. Proc Natl Acad Sci U S A 2012;109:887-92.

[139] Hackl D, Loschko J, Sparwasser T, Reindl W, Krug AB. Activation of dendritic cells via TLR7 reduces Foxp3 expression and suppressive function in induced Tregs. Eur J Immunol 2011:1334-43.

[140] Colonna M. Toll-like receptors and IFN-alpha: partners in autoimmunity. J Clin Invest 2006;116:2319-22.

[141] Wagner H. Endogenous TLR ligands and autoimmunity. Adv Immunol 2006;91: 159-73.

[142] Wang YZ, Yan M, Tian FF, Zhang JM, Liu Q, Yang H, et al. Possible involvement of Toll-like receptors in the pathogenesis of myasthenia gravis. Inflammation 2013;36:121-30.

[143] Savino W. The thymus is a common target organ in infectious diseases. PLoS Pathog 2006;2:e62.

[144] Bernasconi P, Barberis M, Baggi F, Passerini L, Cannone M, Arnoldi E, et al. Increased toll-like receptor 4 expression in thymus of myasthenic patients with thymitis and thymic involution. Am J Pathol 2005;167:129-39.

[145] Fujinami RS, Oldstone MB. Amino acid homology between the encephalitogenic site of myelin basic protein and virus: mechanism for autoimmunity. Science 1985;230:1043-5.

[146] Korn IL, Abramsky O. Myasthenia gravis following viral infection.Eur Neurol $1981 ; 20$ [435-9U]. 
[147] Bhibhatbhan A, Kline G, Vincent A, Toth C. Anti-MuSK myasthenia gravis presenting with Epstein-Barr virus-associated mononucleosis and immunemediated diabetes mellitus. Muscle Nerve 2007;36:264-6.

[148] Verma A, Berger J. Myasthenia gravis associated with dual infection of HIV and HTLV-I. Muscle Nerve 1995;18:1355-6.

[149] Schwimmbeck PL, Dyrberg T, Drachman DB, Oldstone MB. Molecular mimicry and myasthenia gravis. An autoantigenic site of the acetylcholine receptor alpha-subunit that has biologic activity and reacts immunochemically with herpes simplex virus. J Clin Invest 1989;84:1174-80.

[150] Stefansson K, Dieperink ME, Richman DP, Gomez CM, Marton LS. Sharing of antigenic determinants between the nicotinic acetylcholine receptor and proteins in Escherichia coli, Proteus vulgaris, and Klebsiella pneumoniae. Possible role in the pathogenesis of myasthenia gravis. N Engl J Med 1985;312:221-5.

[151] Tindall RS, Cloud R, Luby J, Rosenberg RN. Serum antibodies to cytomegalovirus in myasthenia gravis: effects of thymectomy and steroids. Neurology 1978;28: 273-7.

[152] Klavinskis LS, Willcox N, Oxford JS, Newsom-Davis J. Antivirus antibodies in myasthenia gravis. Neurology 1985;35:1381-4.

[153] Csuka D, Banati M, Rozsa C, Fust G, Illes Z. High anti-EBNA-1 IgG levels are associated with early-onset myasthenia gravis. Eur J Neurol 2012;19:842-6.

[154] Ascherio A, Munger KL, Lennette ET, Spiegelman D, Hernan MA, Olek MJ, et al. Epstein-Barr virus antibodies and risk of multiple sclerosis: a prospective study. JAMA 2001;286:3083-8.

[155] Aoki T, Drachman DB, Asher DM, Gibbs Jr CJ, Bahmanyar S, Wolinsky JS. Attempts to implicate viruses in myasthenia gravis. Neurology 1985;35:185-92.

[156] Klavinskis LS, Willcox HN, Richmond JE, Newsom-Davis J. Attempted isolation of viruses from myasthenia gravis thymus. J Neuroimmunol 1986;11:287-99.
[157] McGuire LJ, Huang DP, Teoh R, Arnold M, Wong K, Lee JC. Epstein-Barr virus genome in thymoma and thymic lymphoid hyperplasia. Am J Pathol 1988;131: 385-90.

[158] Cavalcante P, Barberis M, Cannone M, Baggi F, Antozzi C, Maggi L, et al. Detection of poliovirus-infected macrophages in thymus of patients with myasthenia gravis. Neurology 2010;74:1118-26.

[159] Cavalcante P, Serafini B, Rosicarelli B, Maggi L, Barberis M, Antozzi C, et al. Epstein - Barr virus persistence and reactivation in myasthenia gravis thymus. Ann Neurol 2010;67:726-38.

[160] Niller HH, Wolf H, Ay E, Minarovits J. Epigenetic dysregulation of Epstein-Barr virus latency and development of autoimmune disease. Adv Exp Med Biol 2011;711:82-102.

[161] Cavalcante P, Maggi L, Colleoni L, Caldara R, Motta T, Giardina C, et al. Inflammation and Epstein-Barr virus infection are common features of myasthenia gravis thymus: possible roles in pathogenesis. Autoimmun Dis 2011;2011:213092.

[162] Iwakiri D, Zhou L, Samanta M, Matsumoto M, Ebihara T, Seya T, et al. EpsteinBarr virus (EBV)-encoded small RNA is released from EBV-infected cells and activates signaling from Toll-like receptor 3. J Exp Med 2009;206:2091-9.

[163] Ning S. Innate immune modulation in EBV infection. Herpesviridae 2011;2:1.

[164] Kakalacheva K, Maurer MA, Tackenberg B, Munz C, Willcox N, Lunemann JD. Intrathymic Epstein-Barr virus infection is not a prominent feature of myasthenia gravis. Ann Neurol 2011;70:508-14.

[165] Meyer M, Hols AK, Liersch B, Leistner R, Gellert K, Schalke B, et al. Lack of evidence for Epstein-Barr virus infection in myasthenia gravis thymus. Ann Neurol 2011;70:515-8.

[166] Serafini B, Cavalcante P, Bernasconi P, Aloisi F, Mantegazza R. Epstein-Barr virus in myasthenia gravis thymus: a matter of debate. Ann Neurol 2011;70:519.

\section{Anti-ganglioside antibodies are not useful as a serological marker of neuropsychiatric involvement in patients with systemic lupus erythematosus [USED]}

Anti-ganglioside antibodies (AGA) have been proposed as putative serological markers of neuropsychiatric systemic lupus erythematosus (SLE), but recent findings are controversial. These autoantibodies are involved in the pathogenesis of several peripheral immune-mediated neuropathies. In order to investigate the potential role of AGA in neuropsychiatric SLE, Labrador-Horrillo et al. (Lupus 2012;21:611-5) tested the presence of AGA in the sera of a large cohort of consecutive SLE patients with or without active neurological involvement according to the 1999 ACR criteria for neuropsychiatric lupus syndromes. IgG or IgM AGA specific for different ganglioside antigens were detected by standard ELISA and confirmed by thin layer chromatography. AGA, mainly of the IgM isotype and specific for GM1 ganglioside, were exclusively found in about 30\% of SLE patients with neurospychiatric involvement, but they did not correlate with any neurological manifestation in particular. Thus, the authors concluded that serum AGA are not useful as biomarkers of neurological complications in SLE patients.

Anna Ghirardello 